\title{
SHEAR STRENGTHENING OF T CROSS SECTION REINFORCED CONCRETE BEAMS BY NEAR SURFACE MOUNTED TECHNIQUE
}

\author{
Salvador J. E. Dias ${ }^{1}$, Joaquim A. O. Barros ${ }^{2}$
}

\begin{abstract}
With the purpose of evaluating the influence of both the percentage and inclination of the CFRP laminates on the effectiveness of the NSM technique for the shear strengthening of reinforced concrete $\mathrm{T}$ beams, an experimental program was carried out, using three percentages of laminates and, for each one, three inclinations: $90^{\circ}, 60^{\circ}$ and $45^{\circ}$. The CFRPstrengthened beams had a steel stirrup reinforcement ratio $\left(\rho_{s w}\right)$ of $0.1 \%$. The highest CFRP percentage was designed to provide a maximum load similar to the one of a reference beam reinforced with $\rho_{s w}$ equal to $0.24 \%$. Although these beams have had a similar maximum load, the beams with CFRP presented higher stiffness. Laminates at $60^{\circ}$ was the most effective shear strengthening configuration, having provided a maximum increase in the load capacity of $33 \%$. The contribution of the CFRP strengthening systems was limited by the concrete tensile strength. Below certain spacing between laminates, a group effect occurs due to the interference between consecutive concrete failure surfaces, leading to the detachment of "two lateral walls" from the underlying beam core.
\end{abstract}

CE Database subject headings: NSM technique; CFRP laminates; Shear strengthening; Concrete beams

\footnotetext{
${ }^{1}$ PhD student, ISISE, Dept. of Civil Engineering, Univ. of Minho, Campus de Azurém, 4810-058 Guimarães, Portugal. E-mail: sdias@civil.uminho.pt

${ }^{2}$ Associate Professor, ISISE, Dept. of Civil Engineering, Univ. of Minho, Campus de Azurém, 4810-058 Guimarães, Portugal. E-mail: barros@civil.uminho.pt; Corresponding author
} 


\section{Introduction}

Carbon Fiber Reinforced Polymer (CFRP) materials have high potential for manufacturing effective strengthening systems to increase the shear resistance of RC beams, since they are lightweight, have good corrosion resistance and exhibit high tensile strength. Wet lay up CFRP sheets, bonded to either beam lateral faces or to lateral and tensile bottom faces (Externally Bonded Reinforcement technique, EBR), in continuous or discrete arrangements (Khalifa and Nanni 2000), have been the most researched and applied shear strengthening systems. If anchorage systems are not used (Sato et al. 1997; Khalifa and Nanni 2000), or if CFRP configurations do not embrace the element to strengthen (Adhikary et al. 2004), experimental research has shown that the maximum tensile stress that can be introduced in the CFRP materials, when the EBR technique is applied is, in general, a small percentage of the tensile strength of the material, since, premature debonding of the CFRP is the mandatory failure mode (Bousselham and Chaallal 2004). In an attempt at developing a more effective technique for structural shear strengthening, De Lorenzis and Nanni (2001) proposed the Near Surface Mounted (NSM) technique that consists of fixing round bars into the grooves opened on the concrete cover of the beam lateral faces using epoxy adhesive as a bonding material. Installation of these bars requires the opening of square cross section grooves, which is a relatively time consuming procedure. Furthermore, the thickness of the adhesive material is non-uniform around the bar and the ratio between the bar bond perimeter and the area of bar cross section is lower than the values that could have been obtained if a more appropriate geometric configuration had been adopted for CFRP reinforcement, which would have had consequences in terms of strengthening effectiveness (El-Hacha and Rizkalla 2004). Barros and Dias (2003) proposed the use of CFRP laminates of a $10 \times 1.4 \mathrm{~mm}^{2}$ cross section area that are installed into thin slits, which are easily made by conventional saw cut equipment. A nearly constant thickness of the two adhesive layers binding the laminate to the 
concrete is assured, and the ratio between the bond perimeter and the area of cross section for the laminates is, theoretically, higher than the ratio for round bars. The influence of both the percentage and inclination of the laminates, as well as the effect of beam depth on the performance of the NSM technique for the shear strengthening of small rectangular RC beams without internal stirrups was recently studied (Barros and Dias 2006). Furthermore, effectiveness of the EBR and NSM techniques was compared wherein NSM shear strengthening proved to be the easiest and most effective technique to apply. To evaluate the effectiveness of NSM with CFRP laminates as a shear strengthening technique for real-casesituations, an experimental program composed of $\mathrm{T}$ cross section $\mathrm{RC}$ beams, with a certain percentage of steel stirrups, was carried out. The influence of both the percentage and the inclination of CFRP is discussed, and the main results and failure modes are presented and analyzed.

\section{Experimental Program}

\section{Beam Prototypes and Test Setup}

Fig. 1 presents the $\mathrm{T}$ cross section of the twelve beams comprising the experimental program. The reinforcement systems were designed to assure shear failure mode for all the tested beams. To localize shear failure in only one of the beam shear spans, a three point load configuration of a distinct length of the beam shear spans was selected, as shown in Fig. 1. The monitored beam span $\left(\mathrm{L}_{1}\right)$ is 2.5 times the effective depth of the beam $\left(\mathrm{L}_{1} / \mathrm{d}=2.5\right)$, since, according to the available research (Collins and Mitchell 1997), this is the minimum a/d value with negligible arch effect. To avoid shear failure in the $L_{r}$ beam span, steel stirrups $66 @ 75 \mathrm{~mm}$ were applied in this span. The differences between the tested beams are restricted to the shear reinforcement systems applied in the $\mathrm{L}_{1}$ beam span. The experimental program (see Table 1) is made up of one beam without any shear reinforcement ( $\mathrm{C}-\mathrm{R}$ beam); one beam 
with steel stirrups $\phi 6 @ 300 \mathrm{~mm}$ (2S-R beam, with a percentage of stirrups, $\rho_{s w}$, of $\left.0.10 \%\right)$; one beam with steel stirrups $\phi 6 @ 130 \mathrm{~mm}\left(6 \mathrm{~S}-\mathrm{R}\right.$ beam, $\left.\rho_{s w}=0.24 \%\right)$; and nine beams of ф6@300mm. These last beams also include distinct CFRP arrangements on the $\mathrm{L}_{1}$ beam span: three distinct percentages of CFRP laminates $\left(\rho_{f w}\right)$ and, for each CFRP percentage, three inclinations for the laminates $\left(\theta_{f}\right), 90^{\circ}, 60^{\circ}$ and $45^{\circ}$ (angle between the CFRP fiber direction and the beam axis). The CFRP shear strengthening percentage, $\rho_{f w}$, was obtained from:

$$
\rho_{f w}=\frac{2 \cdot a_{f} \cdot b_{f}}{b_{w} \cdot s_{f} \cdot \sin \theta_{f}}
$$

where $a_{f}=1.4 \mathrm{~mm}$ and $b_{f}=10 \mathrm{~mm}$ are the dimensions of the laminate cross section. In equation (1), $b_{w}=180 \mathrm{~mm}$ is the beam web width and $s_{f}$ represents the spacing of the laminates. For the three series of beams with laminates of distinct orientations, the highest $\rho_{f w}$ in each series was evaluated to assure that the corresponding beams had a maximum load similar to the beam reinforced with the highest $\rho_{s w}(\phi 6 @ 130 \mathrm{~mm}$, the $6 \mathrm{~S}-\mathrm{R}$ beam $)$. In the evaluation of the maximum $\rho_{f w}$, it was assumed that CFRP works like a steel stirrup. However, instead of considering the yield stress of the material, a stress in the laminates corresponding to a strain of $0.5 \%$ was adopted since this is a compromise between the maximum value recommended by ACI (2002) for the EBR $(0.4 \%)$, and the $0.59 \%$ value obtained in pullout bending tests with NSM strengthening technique using CFRP laminates (Sena-Cruz and Barros 2004). Following this approach, the arrangements indicated in Table 1 and Fig. 2 were adopted: eight laminates in each of the beam lateral faces for $\theta_{f}=90^{\circ}$ and $\theta_{f}=45^{\circ}$; seven laminates in each of the beam lateral faces for $\theta_{f}=60^{\circ}$. For the lowest and intermediate $\rho_{f w}$, the $s_{f}$ for each $\theta_{f}\left(90^{\circ}, 60^{\circ}\right.$ and $\left.45^{\circ}\right)$ was obtained with the purpose that the contribution of the CFRP would be similar. Independent of laminate orientation for beams 
with the lowest $\rho_{f w}$, three laminates were applied on each lateral face of the beam, while five laminates were bound for the intermediate $\rho_{f w}$. The laminates were distributed along the $\mathrm{AB}$ line represented in Fig. 1, where A represents beam support at its "test side" and B is obtained assuming a load degradation at $45^{\circ}$.

The three point beam bending tests (Fig. 1) were carried out using a servo closed-loop control equipment, taking the signal read in the LVDT, placed at the loaded section, to control the test at a deflection ratio of $0.01 \mathrm{~mm} / \mathrm{s}$. To avoid concrete spalling at the most loaded beam support, a confinement system based on the use of wet lay-up CFRP sheets (three layers with the fibers direction coinciding with the beam axis direction) was applied according to the configuration illustrated in Fig. 1.

With the purpose of obtaining the strain variation along the laminate with the highest probability of providing the largest contribution for the shear strengthening of the RC beam, four strain gauges (SG_L) were bonded according to the arrangement represented in Fig. 3. Adopting the same principle, one steel stirrup was monitored with three strain gauges (SG_S) installed according to the configuration represented in Fig. 3. The location of the monitored laminates and stirrups in the tested beams is represented in Fig. 2.

\section{Materials}

The concrete compressive strength was evaluated at 28 days and at the age of tests of the beams, carrying out direct compression tests with cylinders of $150 \mathrm{~mm}$ diameter and $300 \mathrm{~mm}$ height, according to EN 206-1 (2000). In the tested beams, high bond steel bars of 6, 12, 16 and $25 \mathrm{~mm}$ diameter were used. The values of their main tensile properties were obtained from uniaxial tension tests performed according to the recommendations of EN 10002 (1990). The properties of the CFK 150/2000 S\&P laminates, under tension, were characterized by uniaxial tension tests carried out according to ISO 527-5 (1997). Table 2 
includes the average values obtained from these experimental programs. The properties of the MBrace Resin 220 adhesive used to bond the laminates to the concrete are also included in this table.

\section{Strengthening Technique}

The strengthening technique is composed of the following procedures: 1) using a diamond cutter, slits of about $5 \mathrm{~mm}$ width and 12-15 $\mathrm{mm}$ depth were opened on the concrete cover (of about $22 \mathrm{~mm}$ thickness) of the lateral faces of the beam web, according to the pre-defined arrangement for the laminates (the laminates were not anchored to the beam flange, they were restricted to the beam web); 2) the slits were cleaned by compressed air; 3) the laminates were cleaned with acetone; 4) the epoxy adhesive was produced according to supplier recommendations; 5) the slits were filled with the adhesive; 6) the adhesive was applied on the faces of the laminates; and 7) the laminates were inserted into the slits and adhesive in excess was removed. To guarantee a proper curing of the adhesive, at least one week passed between the beam strengthening operations and the beam test.

\section{Results}

\section{Beam Load Carrying Capacity}

Table 3 includes for all beams with CFRP laminates the maximum value of the ratio between the load increment provided by the shear strengthening system $(\Delta F)$, after the formation of the first shear crack in the $2 \mathrm{~S}-\mathrm{R}$ reference beam, and the corresponding load capacity of this reference beam $\left(F^{2 S-R}\right)$, see Fig. 5, resulting in a parameter designated as the strengthening efficacy index, $\left(\Delta F / F^{2 S-R}\right)_{\max }$. Table 3 also includes the deflection at the loaded section when $\left(\Delta F / F^{2 S-R}\right)_{\max }$ occurred, which is designated by $u_{\left(\Delta F / F^{2 S-R}\right)_{\max }}$. Assuming $F_{\max }, F_{\max }^{2 S-R}$ and $F_{\max }^{6 S-R}$ to be the load carrying capacities (maximum force) of all the tested beams, of the $2 \mathrm{~S}-\mathrm{R}$ 
reference beam $(\phi 6 @ 300 \mathrm{~mm})$ and of the 6S-R reference beam ( $\phi 6 @ 130 \mathrm{~mm})$, respectively, the values of $\Delta F_{\max } / F_{\max }^{2 S-R}$ and $F_{\max } / F_{\max }^{6 S-R}$ ratios are indicated in Table $3\left(\Delta F_{\max }=F_{\max }-F_{\max }^{2 S-R}\right)$. The force $v s$ deflection at the loaded-section $\left(u_{L S}\right)$ relationship and the $\left(\Delta F / F^{2 S-R}\right) v s u_{L S}$ relationship are depicted in Figs. 4 to 6 for the minimum, intermediate and maximum $\rho_{f w}$, respectively.

If $F_{\max }^{2 S-R}$ is used for comparison purposes, Table 3 and Figs. 4-6 show that all adopted CFRP strengthening configurations provided an increase in the beam load capacity, regardless of both $\rho_{f w}$ and $\theta_{f}$. The load decay observed in the $2 \mathrm{~S}-\mathrm{R}$ reference beam when a shear crack was formed, which occurred at a load of $177.7 \mathrm{kN}$ for a deflection of $1.56 \mathrm{~mm}$ (see Fig. 5), did not occur in the CFRP shear strengthened beams, revealing that the CFRP delayed the formation and propagation of the shear crack. This results in an increase on the beam stiffness after the deflection corresponding to the formation of the shear crack in the reference beam. The presence of the CFRP delayed the loss of the contribution of the concrete aggregate interlock for the concrete shear resistance and postponed the stage in which the stirrups entered in their plastic phase.

The strengthening arrangements with the lowest $\rho_{f w}$ had the smallest increments in terms of beam load carrying capacity $\left(\Delta F_{\max } / F_{\max }^{2 S-R}\right): 0.3 \%, 4.1 \%$ and $18.7 \%$ for the beams strengthened with vertical laminates (2S-3LV beam), at $45^{\circ}\left(2 \mathrm{~S}-3 \mathrm{LI} 45\right.$ beam) and at $60^{\circ}(2 \mathrm{~S}-$ 3LI60 beam), respectively, see Fig. 4. However, in terms of $\left(\Delta F / F^{2 S-R}\right)_{\max }$, the contribution of the first two strengthening systems was more significant than that reported for $\Delta F_{\max } / F_{\max }^{2 S-R}$ : $13.4 \%$ and $8.7 \%$, respectively (for the 2 S-3LI60 beam $\left(\Delta F / F^{2 S-R}\right)_{\max }=19.6 \%$ ), indicating that these two solutions provided a considerable contribution to the beam stiffness.

In terms of the beam load carrying capacity, the level of strengthening efficacy provided by 
the three orientations for the laminates, when the intermediate $\rho_{f w}$ was used, was similar to the level observed for the lowest $\rho_{f w}$. In fact, the strengthening configurations of vertical laminates, laminates at $45^{\circ}$ and laminates at $60^{\circ}$ assured an increase in the beam load carrying capacity of $13.3 \%, 21.9 \%$ and $24.4 \%$, respectively. For the beams strengthened with the intermediate $\rho_{f w}$, only $2 \mathrm{~S}-5 \mathrm{LV}$ and $2 \mathrm{~S}-5 \mathrm{LI} 45$ beams had $\left(\Delta F / F^{2 S-R}\right)_{\max }$ value $(17.3 \%$ and $22.1 \%$ respectively) that exceeded the $\Delta F_{\max } / F_{\max }^{2 S-R}$ value. After the formation of a shear crack in the $2 \mathrm{~S}-\mathrm{R}$ reference beam, the $\left(\Delta F / F^{2 S-R}\right)_{\max }$ values of these strengthened beams was more pronounced than the $\left(\Delta F / F^{2 S-R}\right)_{\max }$ values of the beams strengthened with the lowest $\rho_{f w}$ (compare Figs. 4 and 5 and values in Table 3).

Amongst the beams strengthened with the highest $\rho_{f w}$, the strengthening configuration of $\theta_{f}=60^{\circ}$ was the most effective in terms of maximum load capacity, since an increase of $28.9 \%$ was obtained, while an increase of $25.7 \%$ and $21.3 \%$ was recorded for the strengthening arrangements of $\theta_{f}=90^{\circ}$ and $\theta_{f}=45^{\circ}$, respectively. Regarding $\left(\Delta F / F^{2 S-R}\right)_{\max }$, the efficacy of the strengthening configurations corresponding to $\theta_{f}=45^{\circ}$ and $\theta_{f}=60^{\circ}$ were more relevant, since an increase of $26.5 \%(2 \mathrm{~S}-8 \mathrm{LV}), 28.2 \%(2 \mathrm{~S}-8 \mathrm{LI} 45)$ and $33.0 \%$ (2S7LI60) was registered.

As already mentioned, the highest $\rho_{f w}$ for each strengthening arrangement of the laminates was designed to assure that the beams load carrying capacity was similar to that of the $6 \mathrm{~S}-\mathrm{R}$ reference beam. The obtained experimental results show that, in general, this aim was reached, since the beams with $\theta_{f}=90^{\circ}(2 \mathrm{~S}-8 \mathrm{LV}), \theta_{f}=45^{\circ}(2 \mathrm{~S}-8 \mathrm{LI} 45)$ and $\theta_{f}=60^{\circ}(2 \mathrm{~S}$ 7LI60) had a maximum load of $97 \%, 93 \%$ and $99 \%$ of the maximum load of the $6 \mathrm{~S}-\mathrm{R}$ reference beam, respectively, see Fig. 6 and Table 3. The most notable aspect is, however, that after the shear crack initiation of the $2 \mathrm{~S}-\mathrm{R}$ beam, the strengthened beams demonstrated a 
larger load capacity than the 6S-R reference beam (see Fig. 6b). This improved performance of the strengthened beams derives from the stiffness contribution provided by the laminates. In fact, Fig. 6a shows that, after shear crack initiation, the strengthened beams exhibited stiffer behavior than that the one of the $6 \mathrm{~S}-\mathrm{R}$ beam. At the deflection corresponding to the formation of a shear crack in the $2 \mathrm{~S}-\mathrm{R}$ beam, a load decay occurred in $2 \mathrm{~S}-\mathrm{R}$ and $6 \mathrm{~S}-\mathrm{R}$ reference beams that was more significant in the former beam. The strengthened beams, however, did not show this type of load decay. The considerable number of laminates reinforcing the two concrete lateral cover layers delayed the propagation of the shear cracks to the full width of the beam, which contributed towards the higher stiffness of these beams. The contribution of each CFRP shear strengthening configuration $\left(V_{f}\right)$ was obtained by subtracting from the shear resistance of this beam $\left(V_{r}=0.6 F_{\max }\right)$, the concrete $\left(V_{c}^{C-R}=145.8 \mathrm{kN}\right) \quad$ and the two steel stirrups $\left(V_{s}^{2 S-R}=V_{r}^{2 S-R}-V_{c}^{C-R}=43.2 \mathrm{kN}\right)$ contributions: $V_{f}=V_{r}-V_{c}^{C-R}-V_{s}^{2 S-R}$. From the analysis of $V_{f}$ and $V_{f} / V_{r}^{2 S-R}$ (shear strengthening efficacy) values (Table 3) it is verified that: i) the CFRP configuration of the 2S-7LI60 beam assured a shear resistance increment of $54.6 \mathrm{kN}$, which is similar to the increase $(100.2-43.2=57 \mathrm{kN})$ provided by the shear strengthening solution of the $6 \mathrm{~S}-\mathrm{R}$ beam (four additional steel stirrups); ii) the CFRP configuration of the $2 \mathrm{~S}-8 \mathrm{LV}$ beam assured a contribution of $48.6 \mathrm{kN}$, which corresponds to $85 \%$ of the contribution provided by the four additional steel stirrups of the 6S-R beam; iii) the CFRP contribution of the aforementioned beams, and the contribution of the 2S-5LI45, 2S-8LI45 and 2S-5LI60 beams was higher than $70 \%$ of the contribution provided by shear strengthening solution of the $6 \mathrm{~S}-\mathrm{R}$ beam. The value of $V_{f} / V_{r}^{2 S-R}$ of the $2 \mathrm{~S}-3 \mathrm{LV}$ and $2 \mathrm{~S}-3 \mathrm{LI} 45$ beams was too low. 


\section{Failure Modes}

As expected, all beams failed in shear, with a formation of one or two shear failure cracks, or even a shear band width. Fig. 7 includes details of the shear failure zones of all the tested beams (the steel stirrups at the smaller beam shear span are indicated by vertical lines, and the circles indicate the zone where stirrups ruptured, see also Fig. 2). For the 2S-R (Fig. 7b) and 6S-R (Fig. 7c) beams, the stirrups crossing the shear failure crack ruptured. The angle between the shear failure crack and the longitudinal beam axis was roughly $45^{\circ}, 34^{\circ}$ and $35^{\circ}$ for the C-R, 2S-R and 6S-R beams, indicating that $45^{\circ}$ is the most effective orientation for the laminates in case of beams without steel stirrups, which complies with the results obtained in a previous work (Barros and Dias 2006). Furthermore, $56^{\circ}$ is the most adequate laminate orientation for beams with the percentage of steel stirrups used in the present work.

The failure of the beams with minimum $\rho_{f w}$ was preceded by the "debonding" of the central laminate. However, in the present context, "debonding" should not be assumed as a pure debonding failure mode for the laminate, since along its "bond length", concrete was adhered to the laminate, indicating that failure always occurred due to concrete fracture. In the $2 \mathrm{~S}$ 3LV beam, two shear failure cracks remained active up to the failure of the beam, but each one was only crossed by one laminate with a bond length of about $80 \mathrm{~mm}$, and one stirrup (Fig. 7d). Similar behavior occurred in the 2S-3LI45 beam (Fig. 7g) but, due to the inclination of the CFRP, the central laminate was crossed by the two shear cracks and its bond length was larger $(\approx 125 \mathrm{~mm})$, which contributed towards the higher effectiveness of the CFRP configuration of the 2S-3LI45 beam at failure, when compared to that of the 2S-3LV beam. These are the main reasons that justify the lower efficacy of the CFRP configurations of these beams, when compared to that of the 2S-3LI60 beam, in which the shear failure mode was crossed by two steel stirrups and one laminate with a bond length of about $100 \mathrm{~mm}$ (Fig. 7j). 
The relative position between steel stirrups and laminates also contributes towards the effectiveness of a CFRP shear configuration. In fact, comparing the failure modes of the $2 \mathrm{~S}$ 3LI45 and 2S-3LI60 beams, it is observed that in the former beam the steel stirrup nearest the left beam support (Fig. 7g) intercepted the zone where the laminate has debonded, which did not occur in the 2S-3LI60 beam. This highlights the importance of assuming a homogeneous distance between existent steel stirrups and applied laminates along the shear failure crack, in order to optimize the NSM shear strengthening contribution. Furthermore, when internal stirrups crossing the shear crack begin to considerably debond, the lateral stress component (beam outward) applied by the ribs of the stirrups during its debonding process contributes towards the formation of a tensile concrete failure surface at the interface concrete cover/concrete core of the beam, which promotes the spalling of the concrete cover (Bianco et al. 2006).

In the 2S-5LV beam, a loss of load capacity (Fig. 5) occurred at a deflection of about $5.1 \mathrm{~mm}$ (load decay from $350 \mathrm{kN}$ to $315 \mathrm{kN}$ ) due to the debonding of the laminate at the intermediate position, in one of the beam lateral faces. The other laminates and the stirrups compensated for the contribution loss of this laminate, and the load increased up to $357 \mathrm{kN}$ when one stirrup ruptured, followed by the rupture of the second stirrup. At the maximum load of the 2 S-5LI45 beam $(384 \mathrm{kN})$ the bottom part of the $2^{\text {nd }}$ laminate at the front face of the beam, counted from the beam's support, debonded, followed by the debonding of the top part of the $3^{\text {rd }}$ laminate. Just after the maximum load has been reached, the two stirrups ruptured. In the 2S-5LI60 beam, the load increased up to $392 \mathrm{kN}$ when the central laminate failed due to debonding. Thereafter, the two stirrups crossing the shear failure crack, ruptured.

In the $2 \mathrm{~S}-8 \mathrm{LV}$ beam, at about $380 \mathrm{kN}$, the top part of the $4^{\text {th }}$ laminate at the front face of the beam, counted from the loaded section, debonded with a bond length of about $60 \mathrm{~mm}$. At the maximum load of this beam $(396 \mathrm{kN})$, the lower part of the $5^{\text {th }}$ laminate, at the rear face of 
the beam, debonded with a bond length of about $110 \mathrm{~mm}$. Just after the maximum load was reached, the two stirrups ruptured. The 2 S-7LI60 beam failed due to the debonding of the central laminate in the lower part of the web. This was followed by the debonding of the third laminate, counted from the loaded section, at the top of the web. Finally, the stirrup closest to the loaded section ruptured. In the 2 S-8LI45 beam, at its maximum load ( $382 \mathrm{kN})$, the top part of the $4^{\text {th }}$ laminate at the front face of the beam, counted from the loaded section, debonded, followed by the debonding of the top part of the $5^{\text {th }}$ laminate. From the debonding of the $4^{\text {th }}$ laminate up to the debonding of the $5^{\text {th }}$ laminate, the beam load carrying capacity remained practically unchanged. Just after the debonding of the $5^{\text {th }}$ laminate, the steel stirrups ruptured. At the end of the test, no shear failure crack was visible (Fig. 8c). However, after the concrete cover was removed, a shear crack band became visible, with a width that increased from the top to the bottom of the web (Fig. 7i). This indicates that when a large number of laminates cross a shear crack, the crack-opening arresting mechanisms that the laminates provide promote the rotation of the principal stress directions, resulting in other shear cracks that coalesce in a shear crack band. This shear crack band was observed in all the beams with the highest $\rho_{f w}$ (see Figs. 7f, $7 \mathrm{i}$ and 7l).

With the increase of $\rho_{f w}$, the shear crack pattern was more widespread, which led to lower "bond lengths" for the laminates crossing these cracks. Furthermore, and especially for the maximum $\rho_{f w}$, a group effect occurred due to the relative proximity of the laminates that led to the detachment of the concrete cover of the lateral beam faces. This indicates that the efficacy of NSM shear strengthening might be limited by laminate spacing. Fig.8 shows the influence of CFRP percentage in the failure modes of all tested beams.

As already mentioned, in the reference beams and in $2 \mathrm{~S}-5 \mathrm{LV}$ beam the rupture of the steel stirrups coincided with the maximum load of theses beams. In the remaining beams the rupture of the steel stirrups occurred after the beams have attained their load carrying 
capacity, i.e., in the structural softening phase of the corresponding tests. In this phase the contribution of the laminates for the shear resistance is marginal and steel stirrups are practically the only effective reinforcing elements. In consequence, due to an abrupt increase of crack opening and crack sliding a local gradient of stresses occurred in the section of the steel stirrups crossed by the shear failure crack, leading to the rupture of the steel stirrups.

\section{Strain Distribution in Laminates and Steel Stirrups}

For the strain gauges located in the laminates (SG_L), Table 4 includes the maximum strain values and the strain values at the maximum load of the tested beams. These values show that the average strain $\left(\varepsilon_{C F R P}^{a v g}\right)$ ranged between $0.39 \%$ and $0.84 \%$. In terms of the maximum strain, the values ranged between $0.60 \%$ and $1.11 \%$. In the beams with the highest $\rho_{f w}$, where the crack pattern was more widespread and concrete cover separation occurred, the $\varepsilon_{C F R P}^{a v g}$ was, in general, lower than the $\varepsilon_{C F R P}^{a v g}$ of the beams with the lowest $\rho_{f w}$, where laminates failed due to debonding of the central laminate. As a result of the distinct failure modes, strains in the SGs of the former beams were more uniform than strains in the SGs of the beams with the lowest $\rho_{f w}$. On average, beams with laminates at $60^{\circ}$ presented the highest $\varepsilon_{C F R P}^{a v g} / \varepsilon_{f u}$ ratio (about $42 \%$ ), while beams with vertical laminates and beams with laminates at $45^{\circ}$ had similar $\varepsilon_{C F R P}^{a v g} / \varepsilon_{f u}$ ratio values (about $35 \%$ ). The average $\varepsilon_{C F R P}^{a v g} / \varepsilon_{f u}$ ratio of the tested beams was $37.5 \%$, which corresponds to $\varepsilon_{C F R P}^{a v g}=0.66 \%$. This value is a bit larger than the $0.59 \%$ value proposed by Barros and Dias (2006) for use in an analytical formulation to predict the contribution of the CFRP laminates for the shear strengthening of RC beams, based on the NSM technique (Nanni et al. 2004). On average, the beams with laminates at $60^{\circ}$ presented the highest value of the maximum strain in the CFRP $(0.96 \%)$, while the beams with vertical laminates and laminates at $45^{\circ}$ had a value equal to $0.76 \%$ and $0.84 \%$, respectively. 
To illustrate a representative strain variation in monitored CFRP and stirrups during the beam loading process, the strain values for distinct load levels of the 2S-3LI60 beam are indicated in Table 5, from which it can be observed that the maximum strain value was $1.11 \%$ and was recorded in SG_L2. This SG registered the maximum strain values, since it was the closest to the shear failure crack. For the same reason, SG_L4 recorded the lowest strain values, since it was at the furthest distance from the shear failure crack. The strain values of the monitored stirrups of the 2S-3LI60 and 2S-R beam for three loads levels, included in Table 5, show that the steel stirrup was more strained in the reference beam than in the strengthened beam. The CFRP laminates bridging the faces of the shear failure crack offer some resistance to the crack opening. This mechanism also decreases the loss of the aggregate interlock contribution for the shear resistance that occurs with the crack opening of the shear failure crack. In results of these effects, the strains on the steel stirrups of the CFRP strengthened beams are lower than the strain recorded in the reference beam, at equal load levels applied to the beams. Figs. 9 and 10 represent the variation of the strains on the monitored laminate and stirrup, respectively, during the loading process. Up to the formation of the shear crack, at a loading level of $177 \mathrm{kN}$, the strains in the laminate and in the stirrup were very low. At the formation of the shear crack, the laminates and stirrups were suddenly activated. The SG_L3 was the first to be activated, followed by the SG_L2 and finally, the SG_L4. Up to a load level of about $150 \mathrm{kN}$, only the SG_L3 recorded significant deformation, since the shear crack was crossing the SG_L3 region. Due to the pullout resistance offered by the laminate, a new branch of the shear failure crack formed, crossing the zone where the SG_L2 was placed, which led to an abrupt strain variation in this SG. Due to the pullout resistance of the bond length above the SG_L2, the strain increment in the SG_L3 was also significant, mainly after the stirrups have attained their yield strain at the section crossed by the shear failure crack. Fig. 10 shows that SG_S2 and SG_S3 had a similar variation, since they were almost 
symmetric in relation to the plane of the shear failure crack (see Table 5). At about $340 \mathrm{kN}$, strains measured by SG_S3 and SG_S2 started to decrease. This might be justified by the formation of a new shear crack, which promoted the strain release of the stirrup sections where these SG were installed. A very important aspect of the effectiveness of the NSM technique, regarding the analyzed beams, is its capacity to mobilize the yield strain of the stirrups at the maximum load of the strengthened beams.

\section{Effect of the Percentage and Inclination of the CFRP Strengthening Systems}

Fig. 11 represents the relationship between the strengthening efficacy provided by the CFRP arrangements and $\rho_{f w}$ for the three analyzed shear strengthening configurations (see Table 1 and 3). This figure shows that, regardless of the CFRP percentage, the arrangement of laminates at $60^{\circ}$ was the most effective among the adopted CFRP shear strengthening configurations. Fig. 11 shows that, for the analyzed CFRP percentages, apart from the beam with the highest percentage of laminates at $45^{\circ}\left(2 \mathrm{~S}-8 \mathrm{LI} 45, \rho_{f w}=0.16 \%\right)$, at $F_{\max }$ load level, in the remaining beams, the shear strengthening efficacy increased with the increment of $\rho_{f w}$. However, it seems that the increase of the $F_{\max } / \rho_{f w}$ ratio has a tendency to decrease with the increase of $\rho_{f w}$. This can be justified by the failure mode that occurred in the beams of the highest $\rho_{f w}$.

Fig. 7 shows that the inclination of the shear failure crack decreased with the increase of $\rho_{f w}$, since $40^{\circ}, 40^{\circ}$ and $36^{\circ}$ were the angles measured in the $2 \mathrm{~S}-3 \mathrm{LV}, 2 \mathrm{~S}-5 \mathrm{LV}$ and $2 \mathrm{~S}-7 \mathrm{LV}$ beams, respectively (the inclination of the shear failure crack of the $2 S-R$ beam was $34^{\circ}$ ). This indicates that a strengthening solution with laminates at $90^{\circ}$ is not the most favorable in terms of shear strengthening efficacy. This tendency was also registered in the series with laminates 
at $45^{\circ}\left(45^{\circ}, 36^{\circ}, 36^{\circ}\right.$ in the 2 S-3LI45, 2 S-5LI45 and 2 S-8LI45 beams, respectively). However, in the beams with laminates at $60^{\circ}$, the inclination of the shear failure crack varied from $33^{\circ}$ to $37^{\circ}$, indicating that when laminates are parallel to the principal tensile stresses in the shear critical region, the inclination of the shear failure crack is not too sensitive to the percentage of the $\rho_{f w}$.

\section{Conclusions}

An experimental program was carried out with $\mathrm{T}$ cross section $\mathrm{RC}$ beams that were shear strengthened with CFRP laminates applied according to the NSM technique. The study was developed to highlight the influence of both the inclination $\left(\theta_{f}\right)$ and the shear strengthening percentage of the laminates $\left(\rho_{f w}\right)$. From the obtained results the following observations can be pointed out:

- For deflection levels higher than the one corresponding to the formation of the shear crack in the 2S-R reference beam, all the adopted NSM CFRP shear strengthening configurations provided a significant contribution for the beam load capacity. In terms of beam maximum load, $F_{\max }$, only two CFRP shear strengthening configurations, with the lowest $\rho_{f w}$, had a marginal contribution. The remaining CFRP shear strengthening configurations provided an increase in $F_{\max }$ ranging between $13 \%$ and $29 \%$ of the maximum load of the reference beam, $F_{\max }^{2 S-R}$. For the beams of these last CFRP shear strengthening configurations, $\left(\Delta F / F^{2 S-R}\right)_{\max }$ ranged between $17 \%$ and $33 \%$, where $\Delta F$ is the load increment provided by the shear strengthening configuration after the formation of the shear crack in $2 \mathrm{~S}-\mathrm{R}$ reference beam.

- Regardless of the CFRP percentage, the configuration with laminates at $60^{\circ}$ was the most effective amongst the adopted shear strengthening arrangements. In general, laminates at 
$45^{\circ}$ provided increments in the shear strengthening efficacy larger than those assured by vertical laminates. This is justified by the orientation of the shear failure cracks that had a tendency to be almost orthogonal to the laminates at $60^{\circ}$. However, the results obtained in previous research and the ones of the present experimental program, seem to indicate that the inclination of the shear failure crack decreases with the increase of the percentage of existent steel stirrups, and $45^{\circ}$ is the best inclination of the laminates for beams without existing steel stirrups.

- The highest percentage of CFRP was designed to provide a maximum load similar to that of the $6 \mathrm{~S}-\mathrm{R}$ beam, with a reinforcing system composed of six steel stirrups. The test results validated this purpose. After shear crack formation, the load capacity of the beams shear strengthened with the highest percentage of CFRP was significantly larger than the load capacity of the $6 \mathrm{~S}-\mathrm{R}$ beam. This means that these CFRP shear strengthening arrangements contributed significantly towards the increase of beam stiffness after the formation of the shear crack in the reference beam.

- The load carrying capacity of the beams strengthened according to the NSM technique was conditioned by the concrete tensile strength, since the loss of shear strengthening efficacy of the laminates occurred when they "debonded", bringing a certain concrete volume at the "debond length". Therefore, this failure mechanism can not be assumed as pure debonding since, along the "bond length", concrete adhered to the laminate, indicating that failure occurred due to concrete fracture. The detached concrete volume is conditioned by both the percentage of laminates and the crack pattern formed at the onset of beam failure (which is dependent on the $\left.\rho_{f w}\right)$. For the minimum $\rho_{f w}$ used in the present research program, the laminates were crossed by a reduced number of shear cracks, having led to relatively high "bond lengths". In this case, the laminates failed individually and sequentially. With the increase of $\rho_{f w}$, the shear crack pattern became more widespread, which resulted in lower 
"bond lengths" for the laminates crossing these cracks. Furthermore, and especially for the maximum $\rho_{f w}$, a group effect occurred due to the relative proximity of the laminates, having led to the detachment of the concrete cover of the beam lateral surfaces. This indicates that the efficacy of the NSM shear strengthening might be limited by laminate spacing. The lowest values of the strains in the laminates occurred for the maximum $\rho_{f w}$, which confirms the mentioned loss of effectiveness of the NSM CFRP systems when laminate spacing exceeds a certain limit value. Therefore, a formulation for the prediction of the NSM shear strengthening contribution can not neglect the concrete mechanical properties and the interaction between laminates.

- The distance between the shear reinforcement elements (existent steel stirrups and CFRP laminates) also has an influence in the shear strengthening effectiveness of a CFRP configuration, due to the detrimental interaction effect between the laminates and the stirrups. The best configuration corresponds to the homogeneous distance between existent steel stirrups and applied NSM laminates along the shear failure crack.

\section{Acknowledgements}

The authors of the present work wish to acknowledge the support provided by the "Empreiteiros Casais", $\mathrm{S} \& \mathrm{P} \AA$, degussa ${ }^{\circledR}$ Portugal, and Secil (Unibetão, Braga). The study reported in this paper forms a part of the research program "CUTINSHEAR - Performance assessment of an innovative structural FRP strengthening technique using an integrated system based on optical fiber sensors" supported by FCT, POCTI/ECM/59033/2004. 


\section{Notation}

$$
\begin{aligned}
& A_{s w}=\text { Cross sectional area of steel stirrup } \\
& a_{f}=\text { width of the laminate cross section } \\
& b_{f}=\text { height of the laminate cross section } \\
& b_{w}=\text { width of the beam's web } \\
& d=\text { beam effective depth } \\
& E_{f m}=\text { Average value of the Young Modulus of the CFRP laminate } \\
& F_{\max } \quad \text { load carrying capacity of each beam } \\
& F_{\max }^{2 S-R}=\text { load carrying capacity of } 2 \mathrm{~S}-\mathrm{R} \text { reference beam } \\
& F_{\max }^{6 S-R}=\text { load carrying capacity of } 6 \mathrm{~S}-\mathrm{R} \text { reference beam } \\
& F^{2 S-R}=\text { load of } 2 \mathrm{~S}-\mathrm{R} \text { reference beam for a given deflection } \\
& f_{c m}=\text { Average value of the compressive strength of the concrete } \\
& f_{\text {fum }}=\text { Average value of the maximum tensile strength of the CFRP laminate } \\
& f_{\text {sym }}=\text { Average value of the yield stress of the steel } \\
& f_{\text {sum }}=\text { Average value of the maximum stress of the steel } \\
& \mathrm{L}_{1}=\text { monitored shear span of the beam (smaller beam shear span) } \\
& \mathrm{L}_{\mathrm{r}}=\text { shear span of the beam without CFRP } \\
& \text { SG_L = Strain gauge in laminates } \\
& \text { SG_S = Strain gauge in steel stirrups } \\
& s_{f}=\text { Spacing between laminates } \\
& u_{L S}=\text { deflection at beam loaded-section } \\
& u_{\left(\Delta F / F^{2 S-R}\right)_{\max }}=\text { deflection at beam loaded-section at }\left(\Delta F / F^{2 S-R}\right)_{\max } \\
& V_{c}^{C-R}=\text { concrete contribution for the shear resistance of } \mathrm{C}-\mathrm{R} \text { reference beam }
\end{aligned}
$$




$$
\begin{aligned}
& V_{f}=\text { resistant shear force provided by the CFRP } \\
& V_{r}=\text { beam resistant shear force } \\
& V_{r}^{2 S-R}=\text { resistant shear force in } 2 \mathrm{~S}-\mathrm{R} \text { reference beam } \\
& V_{s}^{2 S-R}=\text { contribution of the two steel stirrups in } 2 \mathrm{~S}-\mathrm{R} \text { reference beam } \\
& \Delta F=\text { Difference between the load capacity of shear strengthened beam with } \\
& \text { CFRP and reference beam (2S-R) for a given deflection } \\
& \Delta F_{\max }=\text { Difference between the maximum load of shear strengthened beam with } \\
& \text { CFRP and the maximum load of reference beam (2S-R) } \\
& \left(\Delta F / F^{2 S-R}\right)_{\max }=\text { maximum value of the ratio between the load increment provided by } \\
& \text { each considered shear strengthening system }(\Delta F) \text {, after the formation of } \\
& \text { the first shear crack in } 2 \mathrm{~S}-\mathrm{R} \text { reference beam, and the corresponding load } \\
& \text { capacity of this reference beam }\left(F^{2 S-R}\right) \\
& \varepsilon_{C F R P}^{\text {avg }}=\text { average strain in the monitored laminate for the maximum load } \\
& \varepsilon_{f u}=\text { maximum value of the CFRP strain } \\
& \theta_{f}=\text { angle between the fibers of the laminate and the beam axis }
\end{aligned}
$$




\section{References}

Adhikary B. B., Mutsuyoshi H., and Ashraf M. 2004. "Shear strengthening of reinforced concrete beams using fiber-reinforced polymer sheets with bonded anchorage." $A C I$ Struct. J., 101(5), 660-668.

American Concrete Institute (ACI). 2002. "Guide for the Design and Construction of Externally Bonded FRP Systems for Strengthening Concrete Structures.” ACI 440.2R-02, Farmington Hills, MI.

Barros J.A.O., and Dias S.J.E. 2003. "Shear strengthening of reinforced concrete beams with laminate strips of CFRP.” Proc., Int. Conference Composites in Constructions - CCC2003, Cosenza, Italy, 289-294.

Barros J. A. O., and Dias S. J. E. 2006. "Near surface mounted CFRP laminates for shear strengthening of concrete beams." Cem. Concr. Compos., 28(3), 276-292.

Bianco V., Barros J.A.O., Monti G. 2006 "Shear Strengthening of RC beams by means of NSM laminates: experimental evidence and predictive models." Technical report 06DEC/E-18, Dep. Civil Eng., School Eng. University of Minho.

Bousselham A., and Chaallal O. 2004. "Shear Strengthening Reinforced Concrete Beams with Fiber-Reinforced Polymer: Assessment of Influencing Parameters and Required Research.”, ACI Struct. J., 101(2), 219-227.

Collins, M. P., and Mitchell, D., Prestresed Concrete Structures, Prentice-Hall, Inc., Englewood Cliffs, New Jersey, 1997.

De Lorenzis L., and Nanni A. 2001. "Shear Strengthening of Reinforced Concrete Beams with NSM Fiber-Reinforced Polymer Rods.” ACI Struct. J., 98(1), 60-68.

El-Hacha R., and Rizkalla S. H. 2004. "Near-surface-mounted fiber-reinforced polymer reinforcements for flexural strengthening of concrete structures." ACI Struct. J., 101(5), 717-726. 
EN 206-1. 2000. "Concrete - Part 1: Specification, performance, production and conformity." European standard, CEN, 69 pp.

EN 10002. 1990. "Metallic materials -Tensile testing - Part 1: Method of test (at ambient temperature).” $35 \mathrm{pp}$.

ISO 527-5. 1997. "Plastics - Determination of tensile properties - Part 5: Test conditions for unidirectional fibre-reinforced plastic composites.", International Organization for Standardization, Genève, Switzerland, 9 pp.

Khalifa, A., and Nanni A. 2000. "Improving Shear Capacity of Existing RC T-Section Beams Using CFRP Composites.”, Cem. Concr. Compos., 22(2), 165-174.

Nanni A., Di Ludovico M., and Parretti R. 2004. "Shear strengthening of a PC bridge girder with NSM CFRP rectangular bars.”, Adv. Struct. Eng., 7(4), 97-109.

Sato Y., Ueda T., Kakuta Y., and Ono S. 1997. "Ultimate Shear Capacity of Reinforced Concrete Beams with Carbon Fiber Sheets." Proc., Third Int. Symposium on Non-Metallic (FRP) Reinforcement for Concrete Structures, Vol. 1, Japan Concrete Institute, Japan, 499-506.

Sena-Cruz J.M., and Barros J.A.O. 2004. "Bond between near-surface mounted CFRP laminate strips and concrete in structural strengthening." J. Comp. Constr., 8(6), 519-527. 


\section{TABLE CAPTIONS}

Table 1. Shear reinforcement systems of the tested beams

Table 2. Values of the properties of intervening materials

Table 3. Relevant results in terms of the load capacity up to beam's failure

Table 4. Strain values in the SG located in the laminates of the tested beams

Table 5. Strain variation in monitored laminate and steel stirrup of 2S-3LI60 beam (strain values in \%o) 
Table 1. Shear reinforcement systems of the tested beams

\begin{tabular}{|c|c|c|c|c|c|}
\hline \multirow[b]{2}{*}{ Beam } & \multicolumn{5}{|c|}{ Shear reinforcement system in the smaller shear span } \\
\hline & Material & Quantity & $\begin{array}{c}\text { Percentage }^{\mathrm{a}} \\
(\%)\end{array}$ & $\begin{array}{c}\text { Spacing } \\
(\mathrm{mm})\end{array}$ & $\begin{array}{c}\text { Angle } \\
\left({ }^{\circ}\right)\end{array}$ \\
\hline $\mathrm{C}-\mathrm{R}$ & - & - & - & & - \\
\hline $2 \mathrm{~S}-\mathrm{R}$ & Steel stirrups & $2 \phi 6$ of two branches & 0.10 & 300 & 90 \\
\hline $6 \mathrm{~S}-\mathrm{R}$ & Steel stirrups & $6 \phi 6$ of two branches & 0.24 & 130 & 90 \\
\hline \multirow{2}{*}{$2 \mathrm{~S}-3 \mathrm{LV}$} & Steel stirrups & $2 \phi 6$ of two branches & 0.10 & 300 & 90 \\
\hline & CFRP & $2 \times 3$ laminates $\left(1.4 \times 10 \mathrm{~mm}^{2}\right)$ & 0.06 & 267 & 90 \\
\hline \multirow{2}{*}{$2 \mathrm{~S}-5 \mathrm{LV}$} & Steel stirrups & $2 \phi 6$ of two branches & 0.10 & 300 & 90 \\
\hline & CFRP & $2 \times 5$ laminates $\left(1.4 \times 10 \mathrm{~mm}^{2}\right)$ & 0.10 & 160 & 90 \\
\hline \multirow{2}{*}{$2 S-8 L V$} & Steel stirrups & $2 \phi 6$ of two branches & 0.10 & 300 & 90 \\
\hline & CFRP & $2 \times 8$ laminates $\left(1.4 \times 10 \mathrm{~mm}^{2}\right)$ & 0.16 & 100 & 90 \\
\hline \multirow{2}{*}{ 2S-3LI45 } & Steel stirrups & $2 \phi 6$ of two branches & 0.10 & 300 & 90 \\
\hline & CFRP & $2 \times 3$ laminates $\left(1.4 \times 10 \mathrm{~mm}^{2}\right)$ & 0.06 & 367 & 45 \\
\hline \multirow{2}{*}{ 2S-5LI45 } & Steel stirrups & $2 \phi 6$ of two branches & 0.10 & 300 & 90 \\
\hline & CFRP & $2 \times 5$ laminates $\left(1.4 \times 10 \mathrm{~mm}^{2}\right)$ & 0.10 & 220 & 45 \\
\hline \multirow{2}{*}{ 2S-8LI45 } & Steel stirrups & $2 \phi 6$ of two branches & 0.10 & 300 & 90 \\
\hline & CFRP & $2 \times 8$ laminates $\left(1.4 \times 10 \mathrm{~mm}^{2}\right)$ & 0.16 & 138 & 45 \\
\hline \multirow{2}{*}{ 2S-3LI60 } & Steel stirrups & $2 \phi 6$ of two branches & 0.10 & 300 & 90 \\
\hline & CFRP & $2 \times 3$ laminates $\left(1.4 \times 10 \mathrm{~mm}^{2}\right)$ & 0.06 & 325 & 60 \\
\hline \multirow{2}{*}{ 2S-5LI60 } & Steel stirrups & $2 \phi 6$ of two branches & 0.10 & 300 & 90 \\
\hline & CFRP & $2 \times 5$ laminates $\left(1.4 \times 10 \mathrm{~mm}^{2}\right)$ & 0.09 & 195 & 60 \\
\hline \multirow{2}{*}{ 2S-7LI60 } & Steel stirrups & $2 \phi 6$ of two branches & 0.10 & 300 & 90 \\
\hline & CFRP & $2 \times 7$ laminates $\left(1.4 \times 10 \mathrm{~mm}^{2}\right)$ & 0.13 & 139 & 60 \\
\hline
\end{tabular}

${ }^{a}$ Stirrups percentage: $\rho_{s w}=\left(A_{s w} /\left(b_{w} d\right)\right) \times 100$ and CFRP percentage: see equation (1). 
Table 2. Values of the properties of intervening materials

\begin{tabular}{|c|c|c|c|c|c|}
\hline \multirow[b]{2}{*}{ Concrete } & \multicolumn{5}{|c|}{ Compressive strength } \\
\hline & \multicolumn{2}{|c|}{$\begin{array}{c}f_{c m}=26.0 \mathrm{MPa} \\
\quad \text { at } 28 \text { days })\end{array}$} & & \multicolumn{2}{|c|}{$\begin{array}{c}f_{c m}=31.1 \mathrm{MPa} \\
\text { (at } 70 \text { days }- \text { age of beam tests) }\end{array}$} \\
\hline \multirow{3}{*}{ Steel } & Tensile strength & $\phi 6$ & $\phi 12$ & $\phi 16$ & $\phi 25$ \\
\hline & $\begin{array}{c}\quad f_{\text {sym }} \\
\text { (yield stress) }\end{array}$ & $533 \mathrm{MPa}$ & $446 \mathrm{MPa}$ & $447 \mathrm{MPa}$ & $444 \mathrm{MPa}$ \\
\hline & $\begin{array}{c}f_{\text {sum }} \\
\text { (maximum stress) }\end{array}$ & $592 \mathrm{MPa}$ & $564 \mathrm{MPa}$ & $561 \mathrm{MPa}$ & $574 \mathrm{MPa}$ \\
\hline \multirow{2}{*}{$\begin{array}{c}\text { CFRP } \\
\text { Laminates }\end{array}$} & \multicolumn{2}{|c|}{$\begin{array}{c}\text { Maximum tensile } \\
\text { strength }\end{array}$} & $\begin{array}{l}\text { Young's } \\
\text { Modulus }\end{array}$ & \multicolumn{2}{|c|}{ Maximum strain } \\
\hline & \multicolumn{2}{|c|}{$f_{\text {fum }}=2952 \mathrm{MPa}$} & $E_{f i n}=166.6 \mathrm{GPa}$ & \multicolumn{2}{|c|}{$\varepsilon_{f u}=1.77 \%^{\mathrm{a}}$} \\
\hline \multirow{2}{*}{ Epoxy adhesive } & \multicolumn{3}{|c|}{ Maximum tensile strength } & \multicolumn{2}{|c|}{ Young's Modulus } \\
\hline & \multicolumn{2}{|c|}{$32 \mathrm{MPa}$} & & \multicolumn{2}{|c|}{$10 \mathrm{GPa}$} \\
\hline
\end{tabular}

${ }^{\mathrm{a}}$ Obtained from Hooke's law. ${ }^{\mathrm{b}}$ According to the supplier. 
Table 3. Relevant results in terms of the load capacity up to beam's failure

\begin{tabular}{|c|c|c|c|c|c|c|c|}
\hline Beam & $\begin{array}{c}\left(\Delta F / F^{2 S-R}\right)_{\max } \\
(\%)\end{array}$ & $\begin{array}{c}u_{\left(\Delta F / F^{2 S-R}\right)_{\text {max }}{ }^{a}}(\mathrm{~mm}) \\
{ }^{a}\end{array}$ & $\begin{array}{l}F_{\max } \\
(\mathrm{kN})\end{array}$ & $\begin{array}{c}\Delta F_{\max } / F_{\max }^{2 S-R} \\
(\%)\end{array}$ & $F_{\max } / F_{\max }^{6 S-R}$ & $\begin{array}{c}V_{f} \\
(\mathrm{kN})\end{array}$ & $\begin{array}{c}V_{f} / V_{r}^{2 S-R} \\
(\%)\end{array}$ \\
\hline C-R & - & - & 243 & - & 0.59 & - & - \\
\hline $2 S-R$ & 0.0 & - & 315 & 0.0 & 0.77 & - & - \\
\hline $6 \mathrm{~S}-\mathrm{R}$ & 30.2 & $7.4(7.4)$ & 410 & 30.2 & 1.00 & - & - \\
\hline $2 \mathrm{~S}-3 \mathrm{LV}$ & 13.4 & $3.84(4.94)$ & 316 & 0.3 & 0.77 & 0.6 & 0.3 \\
\hline $2 \mathrm{~S}-5 \mathrm{LV}$ & 17.3 & $5.05(7.11)$ & 357 & 13.3 & 0.87 & 25.2 & 13.3 \\
\hline $2 \mathrm{~S}-8 \mathrm{LV}$ & 26.5 & $5.1(6.22)$ & 396 & 25.7 & 0.97 & 48.6 & 25.7 \\
\hline 2S-3LI45 & 8.7 & $4.13(5.73)$ & 328 & 4.1 & 0.80 & 7.8 & 4.1 \\
\hline 2S-5LI45 & 22.1 & $5.79(5.92)$ & 384 & 21.9 & 0.94 & 41.4 & 21.9 \\
\hline 2S-8LI45 & 28.2 & $4.8(5.07)$ & 382 & 21.3 & 0.93 & 40.2 & 21.3 \\
\hline 2S-3LI60 & 19.6 & $5.76(5.78)$ & 374 & 18.7 & 0.91 & 35.4 & 18.7 \\
\hline 2S-5LI60 & 24.4 & $5.93(5.93)$ & 392 & 24.4 & 0.96 & 46.2 & 24.4 \\
\hline 2S-7LI60 & 33.0 & $5.04(5.86)$ & 406 & 28.9 & 0.99 & 54.6 & 28.9 \\
\hline
\end{tabular}

${ }^{\mathrm{a}}$ The values in brackets correspond to the deflection at loaded-section at the beam maximum load. 
Table 4. Strain values in the SG located in the laminates of the tested beams

\begin{tabular}{|c|c|c|c|c|c|c|c|}
\hline Beam & $\begin{array}{l}F_{\max }^{\mathrm{a}} \\
(\mathrm{kN})\end{array}$ & $\begin{array}{c}\varepsilon_{C F R P}^{S G} L l \\
(\%)\end{array}$ & $\begin{array}{c}\varepsilon_{C F R P}^{S G L 2} \\
(\%)\end{array}$ & $\begin{array}{c}\varepsilon_{C F R P}^{S G+L 3} \\
(\%)\end{array}$ & $\begin{array}{c}\varepsilon_{C F R P}^{S G \_L 4} \\
(\%)\end{array}$ & $\begin{array}{c}\varepsilon_{C F R P}^{a v g} \\
(\%)\end{array}$ & $\begin{array}{c}\varepsilon_{C F R P}^{a v g} / \varepsilon_{f u}{ }^{\mathrm{b}} \\
(\%)\end{array}$ \\
\hline $2 S-3 L V$ & $316(0)[13]$ & - & 0.78 & 0.37 & - & 0.58 & 33 \\
\hline $2 \mathrm{~S}-5 \mathrm{LV}^{\mathrm{c}}$ & 357 (13) [17] & - & 0.77 & 0.63 & 0.61 & 0.67 & 38 \\
\hline $2 S-8 L^{d}$ & 396 (26) [27] & $0.67(0.67)$ & $0.69(0.72)$ & $0.69(0.54)$ & $0.43(0.31)$ & $0.62(0.56)$ & $35(32)$ \\
\hline 2S-3LI45 & 328 (4) [9] & 0.89 & 0.88 & 1.08 & 0.52 & 0.84 & 47 \\
\hline 2S-5LI45 & $384(22)$ [22] & 0.76 & 0.85 & 0.57 & 0.38 & 0.64 & 36 \\
\hline 2S-8LI45 & $382(21)$ [28] & 0.26 & 0.60 & 0.48 & 0.22 & 0.39 & 22 \\
\hline 2S-3LI60 & 374 (19) [20] & - & 1.11 & 0.98 & 0.23 & 0.77 & 44 \\
\hline $2 \mathrm{~S}-5 \mathrm{LI} 60^{\mathrm{d}}$ & $392(24)$ [24] & $0.74(0.77)$ & $0.89(0.90)$ & $0.84(0.84)$ & - & $0.82(0.84)$ & $46(47)$ \\
\hline $2 \mathrm{~S}-7 \mathrm{LI} 60^{\mathrm{d}}$ & $406(29)$ [33] & $0.47(0.66)$ & $0.85(0.87)$ & $0.73(0.71)$ & $0.46(0.42)$ & $0.63(0.67)$ & $36(38)$ \\
\hline
\end{tabular}

${ }^{a}$ (relative increment load at the beam maximum load in percentage), [strengthening efficacy index in percentage]. ${ }^{b}$ $\left(\varepsilon_{f u}=1.77 \%\right.$ - see Table 2). ${ }^{\mathrm{c}}$ The strain values are referred to the load immediately before the debonding of the monitored laminate. ${ }^{\mathrm{d}}$ The strain values in brackets are referred to the load, at which occurred the maximum strain in the laminates before the maximum load (391 kN in 2S-8LV beam, $389 \mathrm{kN}$ in $2 \mathrm{~S}-5 \mathrm{LI} 60$ beam and $405 \mathrm{kN}$ in $2 \mathrm{~S}-7 \mathrm{LI} 60$ ). 
Table 5. Strain variation in monitored laminate and steel stirrup of 2S-3LI60 beam (strain values in \%)

\begin{tabular}{|c|c|c|c|c|c|c|c|}
\hline \multirow{2}{*}{\multicolumn{3}{|c|}{$\begin{array}{l}\text { Description } \\
\begin{array}{l}\text { The beam failed by debonding of the central laminate } \\
\text { and } F_{\max }=374 \mathrm{kN} \text {. }\end{array}\end{array}$}} & & & & \multicolumn{2}{|l|}{ Monitored stirr } \\
\hline & & & te & $\begin{array}{l}\text { Monitored } \\
\text { laminate }\end{array}$ & & & \\
\hline \multirow{5}{*}{ CFRP } & SG_L & $\mathrm{F}=200 \mathrm{kN}$ & $\mathrm{F}=250 \mathrm{kN}$ & $\mathrm{F}=300 \mathrm{kN}$ & $\mathrm{F}=350 \mathrm{kN}$ & $\mathrm{F}=372 \mathrm{kN}$ & $\mathrm{F}=374 \mathrm{kN}$ \\
\hline & $1^{\mathrm{a}}$ & - & - & - & - & - & - \\
\hline & 2 & 0.32 & 0.57 & 0.78 & 1.00 & 1.11 & 1.11 \\
\hline & 3 & 0.13 & 0.20 & 0.48 & 0.80 & 0.97 & 0.98 \\
\hline & 4 & 0.01 & 0.03 & 0.06 & 0.13 & 0.22 & 0.23 \\
\hline \multirow{4}{*}{$\begin{array}{l}\text { Steel } \\
\text { stirrup }\end{array}$} & SG_S & $\mathrm{F}=200 \mathrm{kN}$ & $\mathrm{F}=250 \mathrm{kN}$ & $\mathrm{F}=300 \mathrm{kN}$ & $\mathrm{F}=350 \mathrm{kN}$ & $\mathrm{F}=372 \mathrm{kN}$ & $\mathrm{F}=374 \mathrm{kN}$ \\
\hline & $1^{b}$ & $\begin{array}{c}0.06 \\
(0.13)\end{array}$ & $\begin{array}{c}0.14 \\
(0.31)\end{array}$ & $\begin{array}{c}0.19 \\
(0.34)\end{array}$ & 0.20 & 0.21 & 0.21 \\
\hline & 2 & $\begin{array}{c}0.19 \\
(0.19)\end{array}$ & $\begin{array}{c}0.34 \\
(1.23)\end{array}$ & $\begin{array}{c}0.92 \\
(0.53)\end{array}$ & 0.46 & 0.38 & 0.38 \\
\hline & 3 & $\begin{array}{c}0.13 \\
(0.13)\end{array}$ & $\begin{array}{c}0.24 \\
(0.26)\end{array}$ & $\begin{array}{c}0.61 \\
(0.42)\end{array}$ & 1.16 & 0.81 & 0.75 \\
\hline
\end{tabular}

Note: To localize the SGs applied in the two arms of the steel stirrup, the arrow which points to the left indicates the SG applied in the arm at the opposite side of the one represented in the Figure. ${ }^{a}$ This SG did not work. ${ }^{b}$ Values in brackets are those recorded in the $2 \mathrm{~S}-\mathrm{R}$ beam at $F_{\max }=315 \mathrm{kN}$. 


\section{FIGURE CAPTIONS}

Fig. 1. Beam prototype (dimensions in $\mathrm{mm}$ )

Fig. 2. Tested beams: localization of the steel stirrups (thick line) and CFRP laminates (dashed line)

Fig. 3. Positions of the strain gauges in the CFRP laminate and steel stirrup

Fig. 4. Beams strengthened with the lowest percentage of CFRP shear strengthening configurations: (a) force $v s$ deflection at the loaded-section, and (b) $\left(\Delta F / F^{2 S-R}\right) v s$ deflection at the loaded-section

Fig. 5. Beams strengthened with the intermediate percentage of CFRP shear strengthening configurations: (a) force $v s$ deflection at the loaded-section, and (b) $\left(\Delta F / F^{2 S-R}\right) v s$ deflection at the loaded-section

Fig. 6. Beams strengthened with the maximum percentage of CFRP shear strengthening configurations: (a) force $v s$ deflection at the loaded-section, and (b) $\left(\Delta F / F^{2 S-R}\right) v s$ deflection at the loaded-section

Fig. 7. Details of the failure zone of the tested beams

Fig. 8. Influence of CFRP percentage on failure modes

Fig. 9. Strains in the monitored CFRP (2S-3LI60 beam)

Fig. 10. Strains in the monitored stirrup (2S-3LI60 beam)

Fig. 11. Strengthening efficacy $v s$ CFRP percentage 


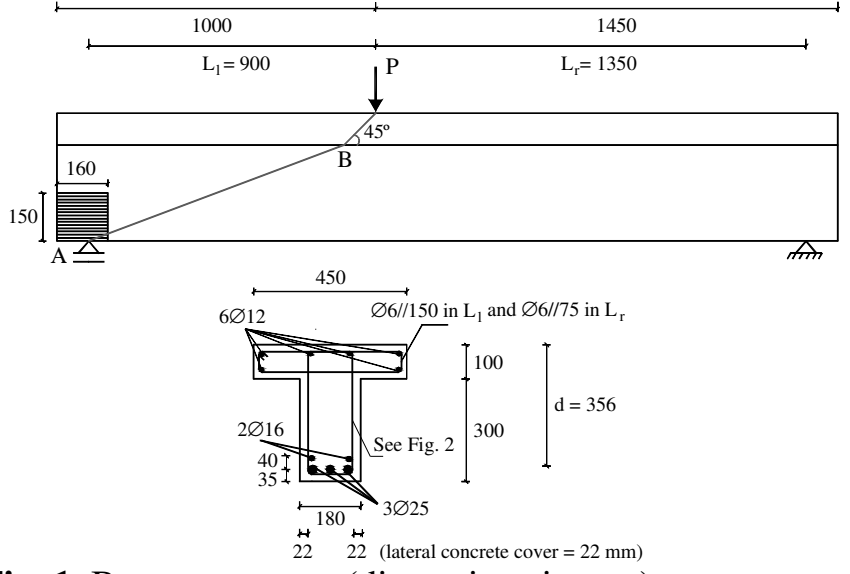

Fig. 1. Beam prototype (dimensions in $\mathrm{mm}$ ) 

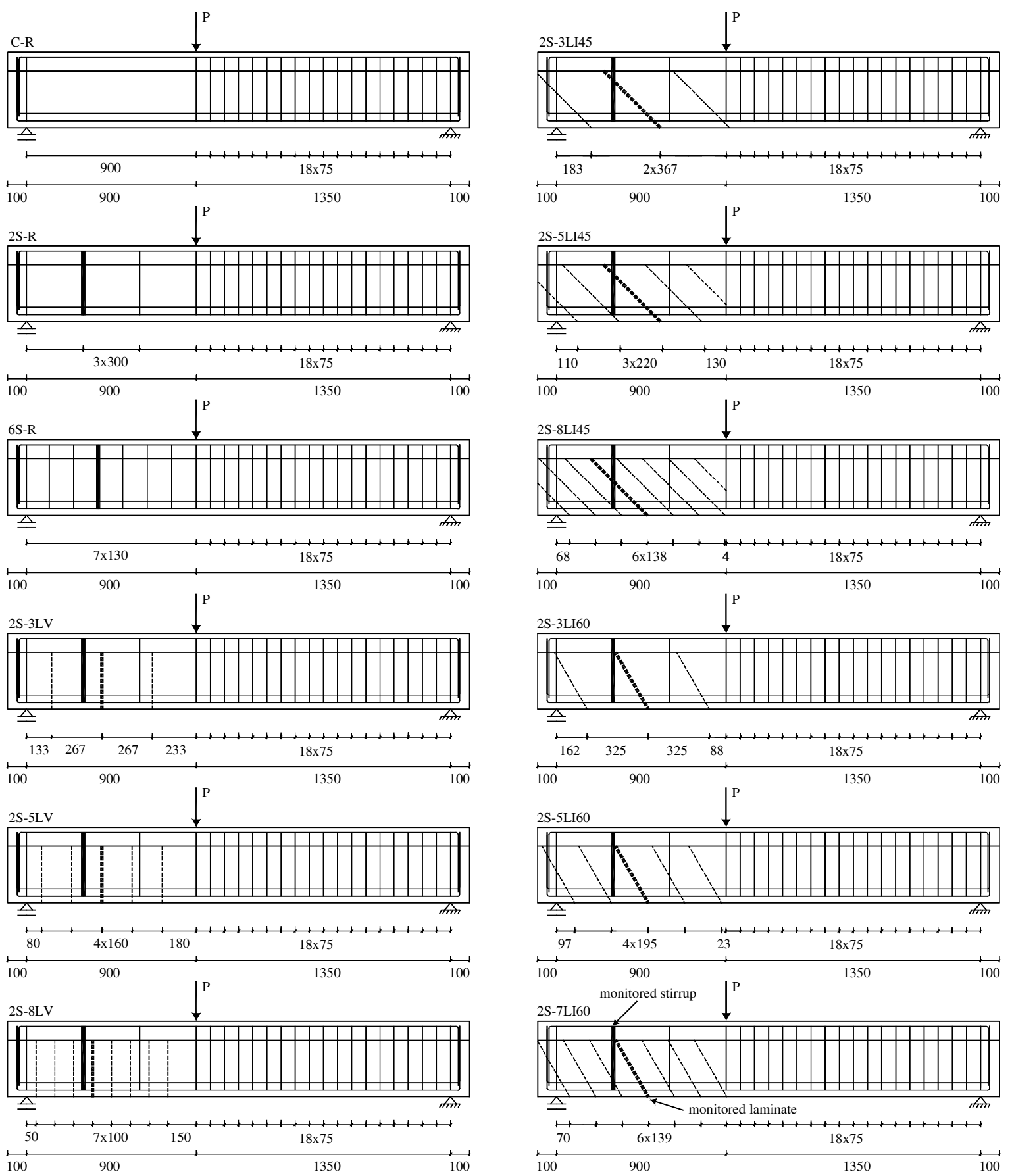

Legend (see example in 2S-7LI60 beam): | monitored stirrup

Notes: The monitored laminate is in the opposite face of the represented one; Apart beams 2S-5LI45 and 2S-5LI60, in the remaining beams, the beam lateral face where the two strain gauges are installed in the arm of the steel stirrup (see Fig. 3) is the same where the monitored laminate was fixed.

Fig. 2. Tested beams: localization of the steel stirrups (thick line) and CFRP laminates (dashed line) 


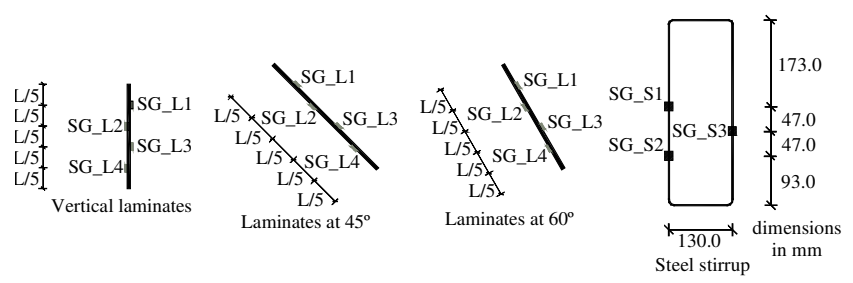

Fig. 3. Positions of the strain gauges in the laminate and stirrup 


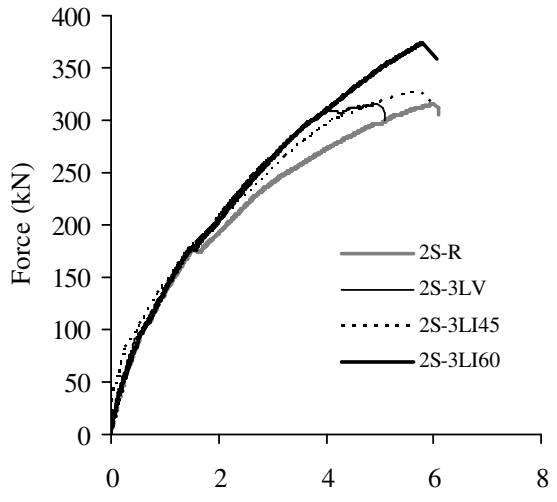

(a)

Deflection at loaded-section ( $\mathrm{mm}$ )

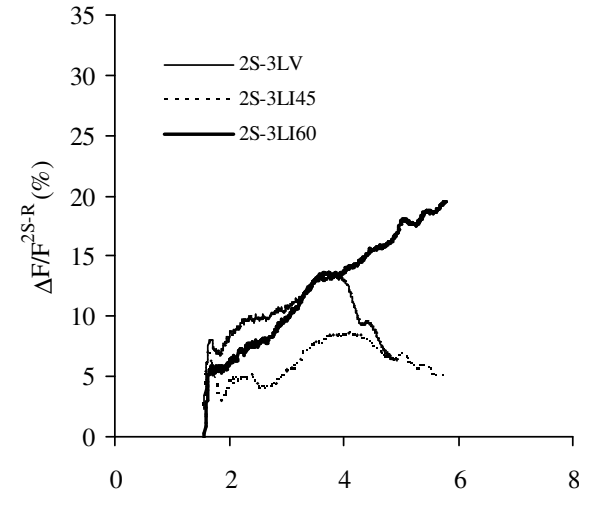

(b)

Deflection at loaded-section (mm)

Fig. 4. Beams strengthened with the lowest percentage of CFRP shear strengthening configurations: (a) force $v s$ deflection at the loaded-section, and (b) $\left(\Delta F / F^{2 S-R}\right) v s$ deflection at the loaded-section 

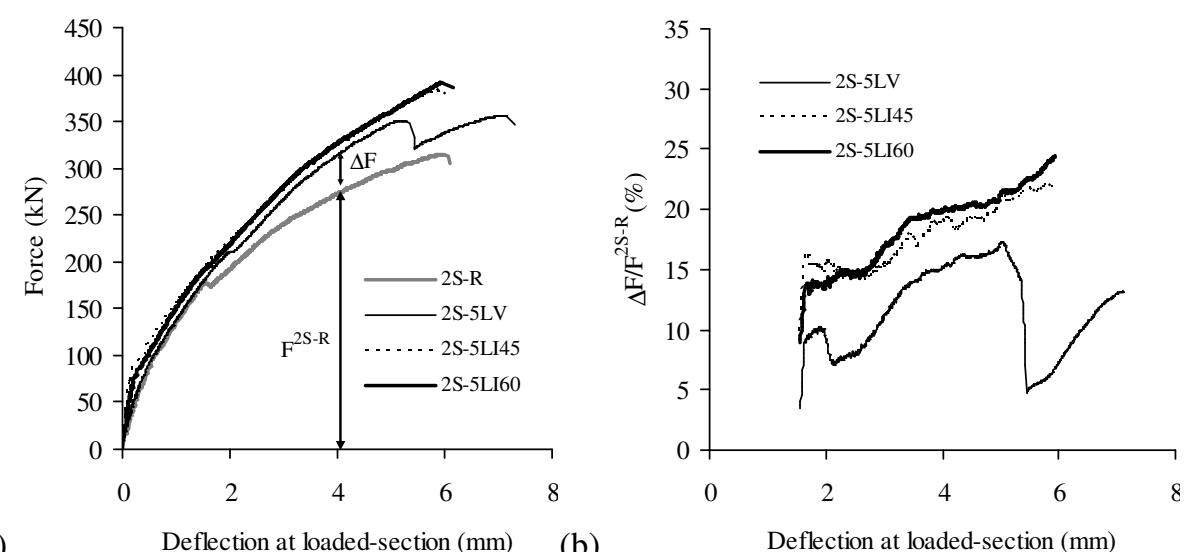

(a) Deflection at loaded-section ( $\mathrm{mm}$ ) (b)

Fig. 5. Beams strengthened with the intermediate percentage of CFRP shear strengthening configurations: (a) force $v s$ deflection at the loaded-section, and (b) $\left(\Delta F / F^{2 S-R}\right) v s$ deflection at the loaded-section 


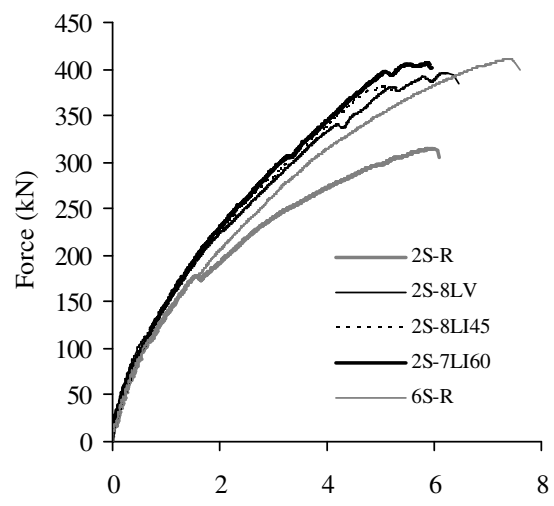

(a)

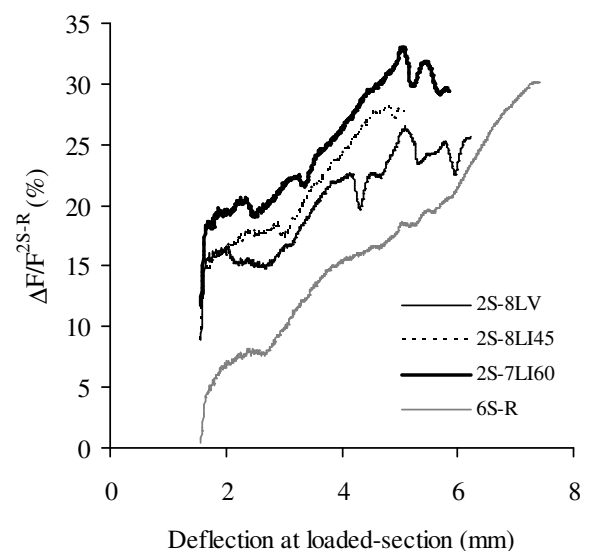

(b)

Fig. 6. Beams strengthened with the maximum percentage of CFRP shear strengthening configurations: (a) force $v s$ deflection at the loaded-section, and (b) $\left(\Delta F / F^{2 S-R}\right)$ vs deflection at the loaded-section 


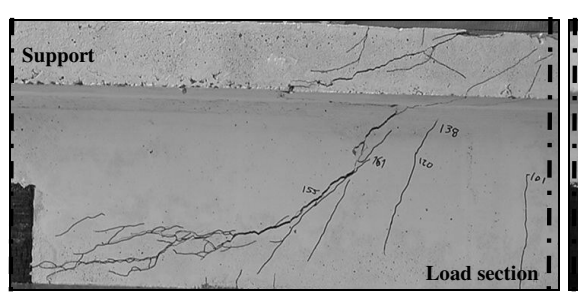

(a) C-R

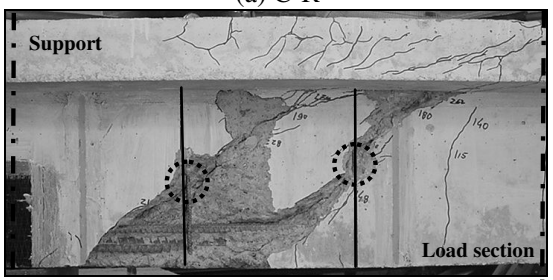

(d) $2 \mathrm{~S}-3 \mathrm{LV}$

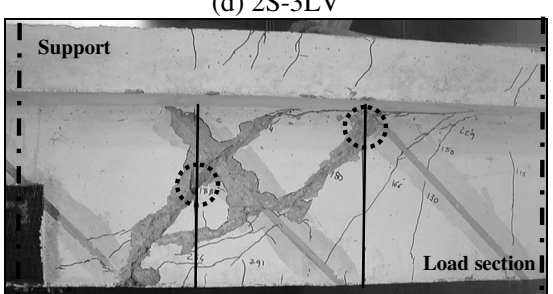

(g) 2S-3LI45

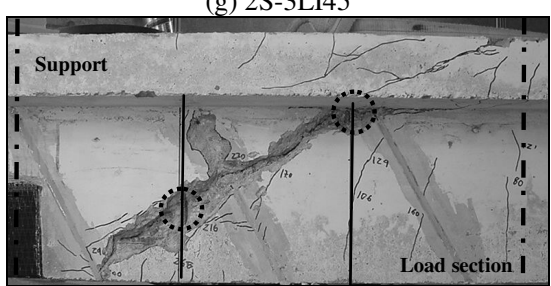

(j) 2S-3LI60

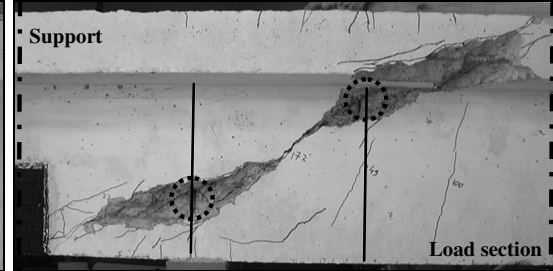

(b) $2 \mathrm{~S}-\mathrm{R}$

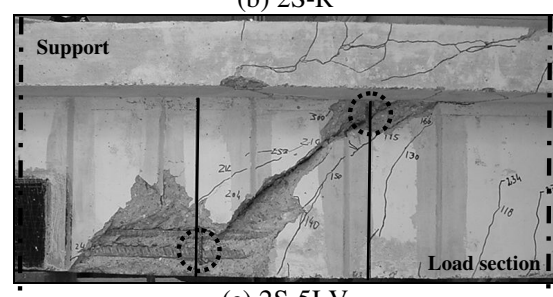

(e) $2 \mathrm{~S}-5 \mathrm{LV}$

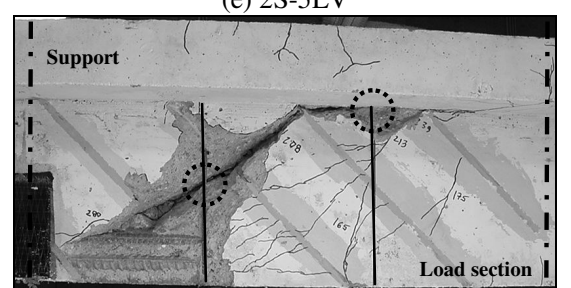

(h) 2S-5LI45

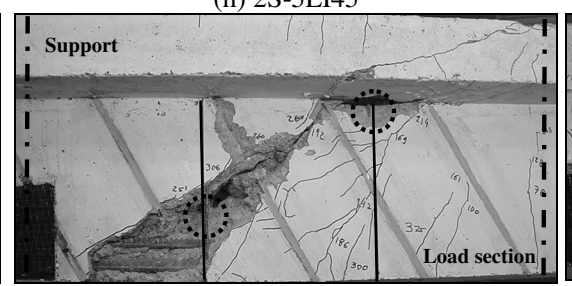

(k) $2 \mathrm{~S}-5 \mathrm{LI} 60$

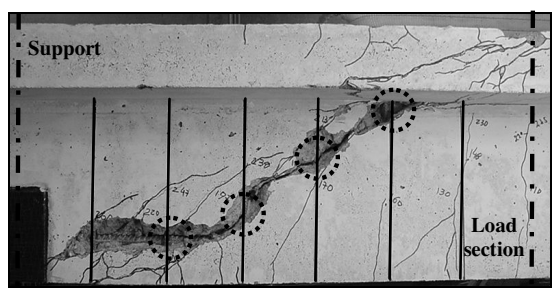

(c) $6 \mathrm{~S}-\mathrm{R}$

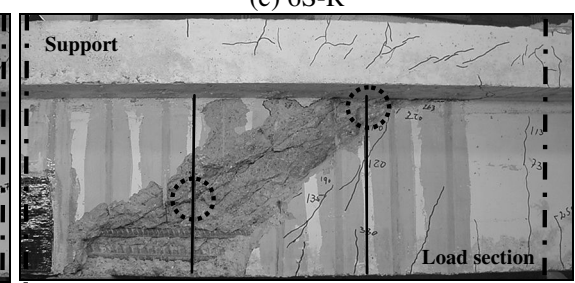

(f) $2 \mathrm{~S}-8 \mathrm{LV}$

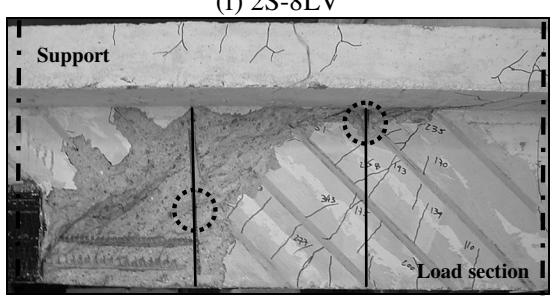

(i) $2 \mathrm{~S}-8 \mathrm{LI} 45$

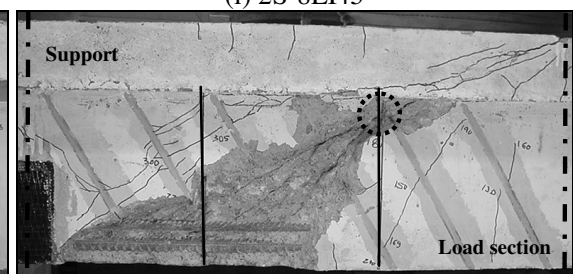

(1) $2 \mathrm{~S}-7 \mathrm{LI} 60$

Fig. 7. Details of the failure zone of the tested beams 


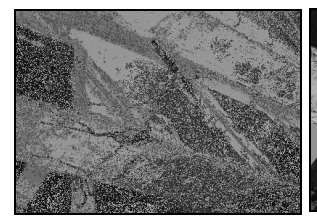

(a) 2S-3LI45

Fig. 8. Influence of CFRP percentage on failure modes (b) 2S-8LI45

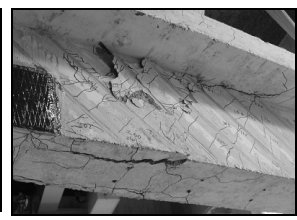

(b) $2 \mathrm{~S}-5 \mathrm{LI} 45$ 


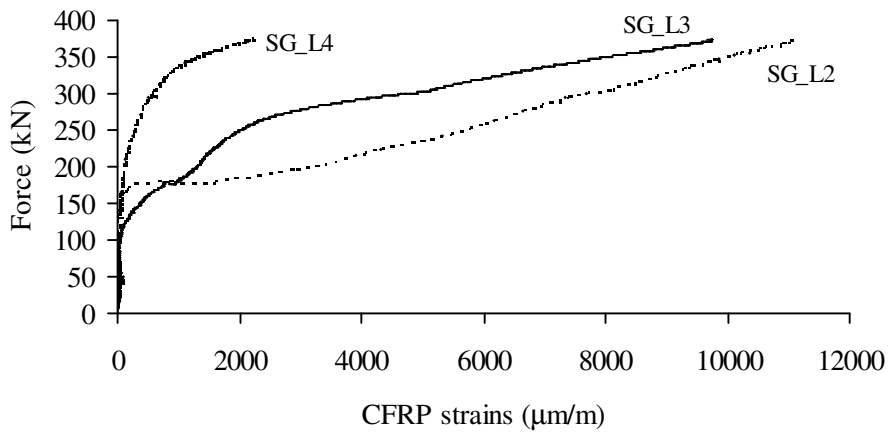

Fig. 9. Strains in the monitored CFRP (2S-3LI60 beam) 


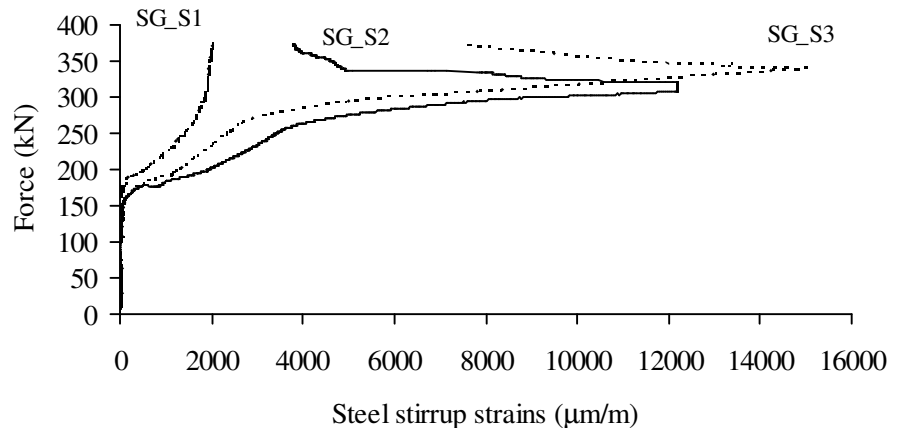

Fig. 10. Strains in the monitored stirrup (2S-3LI60 beam) 


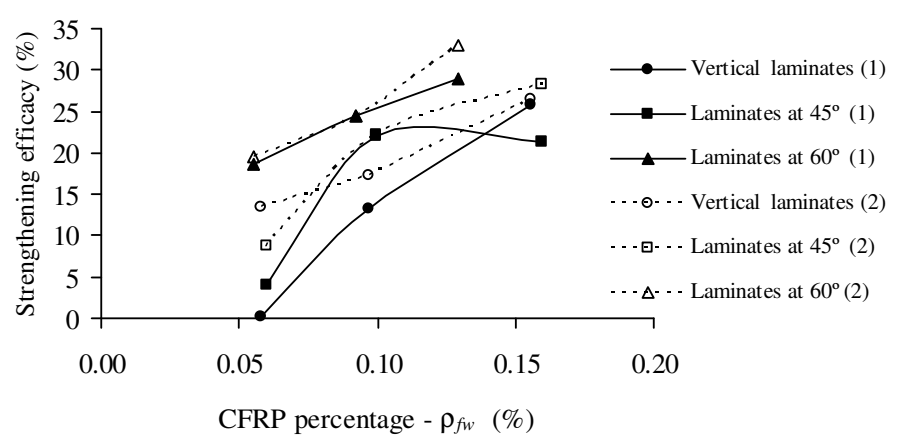

Fig. 11. Strengthening efficacy $v s$ CFRP percentage: (1) in terms of $\Delta F_{\max } / F_{\max }^{2 S-R}$ and (2) in terms of $\left(\Delta F / F^{2 S-R}\right)_{\max }$ 